\title{
O USO DE METODOLOGIAS PARTICIPATIVAS \\ NA INVESTIGAÇÃO COM CRIANÇAS: ALGUMAS \\ CONSIDERAÇÕES A PARTIR DE UMA PESQUISA NA \\ PERIFERIA DE MAPUTO ${ }^{1}$
}

Elena Colonna ${ }^{2}$

Resumo: Este artigo pretende discutir as mais-valias, as dificuldades e os desafios que o uso de metodologias participativas oferece à investigação com crianças, sobretudo em contextos onde as crianças estão pouco habituadas a serem ouvidas e a participar em processos de pesquisa. Tais reflexões nascem na sequência do trabalho realizado numa escola primária da periferia de Maputo, uma pesquisa que se propõe investigar a experiência específica de "ser criança" dos meninos e das meninas que frequentam esta instituição, a partir dos seus próprios pontos de vista. Baseando-se na ideia da Sociologia da Infância, que as crianças como atores sociais plenos, competentes na formulação de interpretações sobre os seus mundos de vida e reveladores das realidades sociais onde se inserem, a pesquisa propõe o uso de uma metodologia compósita, que mobilize uma gama de diferentes métodos e técnicas, quer tradicionais quer inovadores, que permitam escutar a voz das crianças. Os instrumentos de investigação privilegiados são então representados por entrevistas e grupos de discussão (técnicas de caráter oral), fotografias, vídeos, desenhos (técnicas de caráter visual) e registos escritos, ensaios e diários (técnicas escritas).

Palavras-chave: Crianças. Metodologias participativas. Sociologia da Infância. Moçambique.

Abstract: This article discusses the gains, the difficulties and challenges that the use of participatory methodologies offers to research with children, especially in contexts where children are not used to be heard and to participate in research processes. These reflections result from a research done in a primary school in the suburbs of Maputo. The research aims to investigate the specific experience of "being a child" of the children who 
attend this institution, from their own points of view, ando is based on the idea of Sociology of Childhood, which considers children as social actors, competent in formulating interpretations of their life worlds and revealing the social realities in which they live. The research proposes the use of a composite methodology, which mobilizes a range of different methods and techniques, both traditional and innovative, allowing listening to the voices of children. The principal research instruments are represented by interviews and discussion groups (oral techniques), photographs, videos, drawings (visual techniques) and written records, diaries and essays (writing techniques).

Key-words: Children. Participatory methodologies. Sociology of Childhood. Mozambique. 


\section{Introdução: que pesquisa?}

Este artigo pretende apresentar e discutir o trabalho de pesquisa desenvolvido com as crianças de uma escola primária dos arredores da cidade de Maputo, entre os meses de agosto e novembro de 2008. O trabalho foi realizado pela autora no âmbito do seu Doutoramento em Sociologia da Infância. O projeto de investigação, no seu complexo, objetiva conhecer a experiência de "ser criança" das crianças moçambicanas e, nomeadamente, daquelas que frequentam a escola considerada, através do estudo de uma atividade específica que caracteriza a quotidianidade da maioria delas. As observações do contexto e um longo período de permanência e trabalho em contacto direto com as crianças na zona onde a escola se localiza permitiram notar que é prática comum elas desempenharem a tarefa de tomar conta de outras crianças (irmãos mais novos, sobrinhos, primos, vizinhos ou outros), embora com modalidades e em tempos e espaços diferentes. A tarefa de tomar conta de outras crianças foi assim escolhida como fenómeno objeto de estudo da investigação, que pretende ser abordado a partir do ponto de vista das próprias crianças.

Para poder alcançar este objetivo geral, investigando as vivências das crianças em situações da vida quotidiana, os seus espaços e tempos de vida e as relações que estabelecem com outras crianças e com os adultos, considerou-se necessário dividir o trabalho de investigação em duas etapas, sendo que a primeira vai constituir o objeto das considerações apresentadas neste artigo:

- uma primeira fase na escola, para entrar em contacto com as crianças e ter uma visão geral sobre as suas vidas, as suas experiências quotidianas e a maneira como elas as representam. Nesta fase, 
seria também possível identificar as crianças (e as relativas famílias) disponíveis a continuar a participar na investigação;

- uma segunda fase, a realizar durante o período das férias, para acompanhar as rotinas quotidianas das crianças, em casa, no exterior ou em outros locais, consoante às suas deslocações.

A unidade de análise é constituída pelas três turmas da $6^{\mathrm{a}}$ classe da escola, por um total de 120 crianças com idade compreendida entre os 10 e os 15 anos. O interesse em trabalhar com crianças desta classe é motivado, em primeiro lugar, por ter observado que as crianças desta faixa etária têm sido consideradas pelos familiares suficientemente crescidas para assumir um conjunto de responsabilidades em casa e também porque as crianças da $6^{\text {a }}$ classe têm tido um domínio da escrita, tal para permitir também o uso de técnicas de investigação de caráter escrito, entre outras. O grupo de crianças consideradas para o estudo é caracterizado por uma forte heterogeneidade em termos de proveniência da família, bairro de residência, composição familiar e nível socioeconómico. Ainda, existem diferenças significativas entre as crianças no tipo de atividades e nas responsabilidades que assumem no âmbito familiar.

\section{A entrada no campo: o programa e a realidade}

A entrada em campo é crucial na etnografia, porque um dos seus objetivos centrais como método interpretativo é o estabelecimento de um estatuto participante e uma perspetiva interna. (CORSARO; MOLINARI, 2005).

Consciente da relevância deste momento para o desenvolvimento da pesquisa, tentei planificá-lo da maneira mais detalhada e organizada possível. O primeiro contacto com a direção da insti- 
tuição e, em seguida, com as crianças realiza-se em abril de 2008. Depois de ter combinado com o diretor pedagógico que irei trabalhar com as $6^{\mathrm{a}}$ s classes, peço-lhe que me apresente nas três turmas para que eu possa pedir também às crianças o seu consentimento para realizar a pesquisa. Nas duas primeiras salas as crianças parecem muito animadas pela minha presença, algumas me cumprimentam com um gesto da mão, outras com um sorriso e outras piscando o olho. Eu reconheço apenas algumas delas, mas quando o diretor pedagógico me apresenta e pergunta quem delas já me conhece, quase todas levantam a mão. Na terceira sala, as crianças parecem-me muito mais calmas e não consigo ver nenhuma cara conhecida. De facto, trata-se de crianças que estudaram em outras escolas e estão nesta pela primeira vez, desde o princípio deste ano letivo. É por isso que, quando o diretor pergunta quem me conhece, apenas um menino levanta a mão.

Nas três turmas o diretor explica muito brevemente às crianças que eu preciso de fazer um trabalho com elas para a universidade onde estudo, na Europa. Diz que precisarei passar algumas horas com elas na escola para saber um pouco sobre as suas vidas e depois, se eles quiserem, irei também para as suas casas para ver o que fazem, como brincam e outras coisas. Depois diz que, para poder fazer isso, eu preciso saber se eles querem participar ou não. "Queremos", respondem em coro. "Então aceitam?" pergunta de novo. "Aceitamos", respondem sempre em coro. Eu acrescento que gostaria de saber deles o que gostam de fazer, o que gostam de brincar, o que fazem em casa, agradeço pela disponibilidade e informo-as que estarei com elas a partir de agosto.

Desde este primeiro contacto com a instituição até a minha entrada no campo e ao longo do próprio trabalho de investigação, esteve sempre presente a dúvida se trabalhar com todas as três 
turmas ou optar apenas por uma. Tal dúvida tinha base no conflito existente entre as questões éticas relativas à seleção dos participantes na pesquisa (Alderson, 1995; Alderson; Morrow, 2004) e a preocupação com a viabilidade do trabalho e com a criação de uma relação de confiança entre a pesquisadora e as crianças no pouco tempo à disposição antes da conclusão do ano letivo. De facto, se por um lado não queria excluir nenhuma turma, uma vez que na minha primeira entrada na escola todas as crianças tinham aceitado participar, por outro lado, dava-me conta que, em apenas dois meses, seria difícil conhecer profundamente e construir uma relação de cumplicidade, que precisa de proximidade e de tempo, com cada uma das 120 crianças, correndo o risco de acabar por ter um contacto muito superficial com todas elas.

No momento da minha entrada efetiva no campo, em agosto de 2008, discuti com o diretor pedagógico a minha ideia de escolher apenas uma turma entre as duas onde mais crianças me tinham reconhecido mas ele sugeriu que eu pedisse autorização aos pais e começasse o trabalho com as três turmas, para poder mais tarde escolher com qual delas trabalhar. Concordei com a ideia e também planificamos juntos uma entrada bastante gradual na instituição: nas primeiras duas semanas, apareceria na escola apenas nos momentos da entrada, do intervalo e da saída para começar a ter os primeiros contactos mais informais com as crianças; depois entraria nas salas apenas para assistir as aulas dos professores por mais duas semanas; finalmente, ao completar um mês, começaria já a envolver-me diretamente nas atividades de investigação com as crianças dentro e fora das salas de aulas.

Num primeiro momento, tinha pensado numa apresentação da investigação às crianças mais formal, através de um pacote informativo a entregar a cada criança com uma carta para ela, uma para a 
família e outro material útil para o trabalho de pesquisa (O'Kane, 2005; Thomas; O'Kane, 1998) e também com a ajuda de um esquema no quadro ou num cartaz, onde fossem indicados os objetivos, os métodos e a utilização dos dados (Gaitán, 2006; Alderson, 1995). Refletindo sobre a realidade local e sobre a melhor maneira de deixar as crianças esclarecidas, optei por uma apresentação mais simples e menos "escolarizada", através de uma conversa com as crianças na sala de aulas que pudesse ser renovada e aprofundada naquele contexto ou noutro todas as vezes que eu ou elas sentíssemos essa necessidade.

$\mathrm{Na}$ realidade, o projeto de um contacto gradual com as crianças acabou por não acontecer e a minha entrada no campo revelou-se bastante precipitada. De facto, nas primeiras semanas em que deveria frequentar as crianças apenas no tempo e espaço fora da sala de aula, faltaram alguns professores enquanto eu me encontrava no espaço escolar. A diretora da escola pediu-me que eu ficasse na sala de aulas com as crianças e eu acabei por aceitar, achando que seria uma boa oportunidade de poder explicar melhor às crianças o que vinha fazer na escola (um trabalho de investigação para conhecer a vida das crianças moçambicanas e, nomeadamente, da zona onde elas vivem) e para começar a conhecê-las (fazendo um pequeno jogo para conhecer os nomes, as idades e o que cada pessoa gosta de fazer na sua casa).

Tudo correu bem no primeiro encontro com cada turma, mas já no segundo encontro, que aconteceu de repente e eu não tinha planificado o que fazer com as crianças, tive alguns problemas de "disciplina", no sentido que eu não me queria impor de um jeito autoritário, por isso não gritei nem ameacei as crianças (que é o método dos professores ao qual elas estão habituadas), assim elas 
aproveitaram para conversar em voz alta, se deslocar dentro da sala e dançar, o que acabou por incomodar a diretora e os professores das salas ao lado que vieram reclamar.

Decidi então não aceitar mais ficar nas salas, antes de ter a autorização dos pais e as atividades já planificadas, mas tornou-se um pouco difícil negar porque quer a diretora quer as próprias crianças me procuravam para solicitar a minha presença na sala, sempre que faltasse algum professor. Assim comecei logo a desenvolver as primeiras atividades com as crianças nas salas. Ao mesmo tempo, não deixei de estar presente no horário do intervalo, sentada sempre no mesmo banco, disponível para estar com as crianças que quisessem. Considerei essencial este momento porque deixa nas mãos das crianças a liberdade de decisão de vir ter comigo ou não, mesmo que seja apenas para cumprimentar, trocar poucas palavras ou só para estar por perto sem nada querer dizer. Outros tipos de interação poderão assim vir com o tempo e com a relação de confiança que se desenvolver.

\section{A identidade da investigadora: mana, tia, pesquisadora, professora, explicadora, educadora ou Elena?}

Tendo consciência da impossibilidade que uma investigadora adulta, branca, europeia e, por isso, com uma cultura e uma língua materna diferentes consiga compreender completamente a realidade a partir do ponto de vista de uma criança moçambicana e considerando também que dificilmente as crianças estão acostumadas a comunicar livremente e a ser levadas a sério pelos adultos (Punch, 2002a), o principal desafio consiste na construção de uma relação e de um conjunto de ferramentas que ofereçam às crianças o máximo 
de oportunidades de expressar os seus próprios pontos de vista à investigadora.

Ao tentar desenvolver uma investigação com as crianças de forma participativa, parece-nos necessário, em primeiro lugar, tentar desconstruir a ideia de adulto típico que as crianças possuem (Corsaro, 1997), para poder em seguida negociar uma nova relação específica investigador/crianças. Pensamos que as crianças nunca poderão considerar o investigador como um membro efetivo do grupo de pares, mas a fim de facilitar a interação é importante libertar-se das categorias de adulto que regulam a vida e o pensamento das crianças. Na nossa opinião, é preciso analisar a quais destas categorias o investigador mais se aproxima, ou por razões contextuais (por exemplo, trabalhar numa escola aproxima mais o investigador à figura do professor), ou por razões pessoais, como características de género ou também particularidades físicas (por exemplo, uma investigadora mulher com uma atitude materna para com as crianças pode fazer com que a primeira relação que se instaure seja mais do tipo mãe/filho ou um homem com a barba e a barriga grande pode lembrar às crianças o Pai Natal e, por consequência, poderá criar-se inicialmente uma relação mais orientada para a brincadeira).

No caso de uma investigação num lugar diferente do seu contexto de origem (cidade, região ou país), o investigador deve ter em conta os fatores culturais e os estereótipos relacionados à sua proveniência ou à sua nacionalidade. Num contexto como o de Moçambique, os estereótipos são ligados ao facto de "ser estrangeiro" e de "ser branco", mais do que à própria nacionalidade. Trata-se de estereótipos que decorrem dos tempos da colonização, mas também das relações atuais com os "estrangeiros brancos", que em Moçambique são sobretudo turistas, diplomáticos, cooperantes ou religiosos, todas pessoas que, em geral, possuem um nível de vida, económico 
e de instrução muito superior à média moçambicana. Muitas vezes, então, a população moçambicana instaura com os "estrangeiros brancos" uma relação de deferência ou de interesse. Em ambos os casos, trata-se de uma relação que coloca as duas partes em níveis diferentes. De facto, apesar das relações entre brancos e negros terem melhorado, sobretudo ao longo dos últimos trinta anos, séculos de crenças e convicções, de racismo e de colonialismo, não podem ser apagados em poucas décadas (Reviere, 2001).

Assim, no momento em que uma investigadora branca queira realizar uma pesquisa em Moçambique, deve ter em consideração este sistema de relações de superioridade/inferioridade, mas também de esperteza/incompetência. Estes termos podem ser atribuídos, alternativamente, a cada uma das duas partes, dependendo do contexto: por exemplo, um “estrangeiro branco" poderá ser muito esperto em âmbito académico, mas revelar-se totalmente incompetente em muitas atividades quotidianas, como cartar água, fazer compras num mercado ou dançar, enquanto a situação poderia ser invertida para um moçambicano. Mesmo em comparação com as próprias crianças moçambicanas, o adulto branco pode revelar-se incompetente em muitos trabalhos domésticos, uma vez que estas atividades baseiam-se na competência adquirida através da experiência e da prática mais que em características físicas ou biológicas que variam com a idade (Punch, 2003). Por exemplo Márcia e Linda, duas meninas de onze anos que gostam de visitar a investigadora para ajudá-la na cozinha, conseguem descascar e cortar os vegetais, lavar a loiça e limpar o chão muito mais rapidamente do que a própria investigadora adulta. Podemos então resumir, simplificando, que uma investigadora branca que pretende realizar uma investigação com crianças numa escola em Moçambique, se depara com três diferentes níveis de obstáculos, representados por 
um conjunto de estereótipos, que podem afetar a relação com os sujeitos da pesquisa: relação branco/negro, relação professor/aluno, relação criança/adulto.

No caso desta investigação, o primeiro aspeto relativo ao conjunto de papéis e expectativas que regulam a relação entre brancos e negros tem sido em parte resolvido graças aos repetidos períodos de permanência da investigadora na zona ao longo dos últimos três anos e a um ano de trabalho como professora e educadora na instituição onde a pesquisa foi desenvolvida. Estes elementos têm permitido que a presença da investigadora, apesar de ser uma "estrangeira branca”, deixasse de ser excecional e se tornasse familiar. Malinowsky afirma que começou a recolher material interessante para a pesquisa, a partir do momento em que podia atravessar toda a aldeia de ponta a ponta sem que as pessoas parassem as suas atividades para olhar para ele. Do meu lado, posso afirmar que consigo percorrer todo o percurso de casa à escola e vice-versa, sem gerar admiração naqueles que me veem a passar, pelo contrário, cumprimentando a maioria deles.

O segundo obstáculo a ultrapassar é ligado à relação professor/ aluno. Com efeito, se por um lado o facto de já ter trabalhado e ser conhecida na escola e a relativa proximidade quer com os adultos quer com as crianças tem representado um valioso facilitador para a entrada no terreno, por outro lado, tem originado alguma confusão de papéis, ainda mais em um contexto onde a hierarquia e a autoridade são muito consideradas. Nomeadamente, sobretudo num primeiro momento, tenho sido vista como uma professora e isto levou-me talvez a ser "temida" pelas crianças e "mandada" pela diretora. Esta confusão investigadora/professora foi enfatizada pelo facto de a pesquisa ser desenvolvida no tempo e no espaço escolar e por ter sido mandada várias vezes pela diretora a substituir os professores 
na sala de aulas. Eu tentei resolver este problema esclarecendo e sublinhando o meu papel de investigadora no princípio da pesquisa e sempre que se tornasse necessário. Porém, para além das palavras, considero que outros elementos tiveram um peso decisivo em me diferenciar dos outros professores: não gritar, não ameaçar e não bater na sala de aulas; desenvolver algumas atividades em pequenos grupos ao ar livre sentando com as crianças no chão numa roda; partilhar com as crianças o momento do intervalo, sentando com as crianças nos bancos ou no chão, aprendendo as suas brincadeiras, conversando e comendo gelinhos juntos...

O terceiro obstáculo, que tem a ver com as relações entre adultos e crianças, tem sido talvez o mais difícil a ser ultrapassado, sobretudo tratando-se de um país onde o respeito e a obediência aos mais velhos constituem um traço fundamental das relações sociais. As crianças são constantemente mandadas pelos adultos e costumam cumprir as ordens com prontidão, mas também com um certo orgulho. Pelo resto, os mundos dos adultos e o das crianças permanecem fortemente separados, sendo raras as interações entre adultos e crianças orientadas para a conversa, a troca de ideias e de informações, a brincadeira. No meu caso, tenho tentado romper esta separação e aproximar-me ao mundo das crianças através de um conjunto de atitudes, como as indicadas para me diferenciar dos professores, que se afastam das expectativas das crianças sobre os adultos, quer em relação ao que elas acham que me pode agradar ou desagradar, quer a maneira em que elas esperam ser tratadas.

Aos poucos, tenho tentado e talvez conseguido desconstruir estas diferentes imagens que influenciam a minha relação com as crianças, colocando-me numa posição intermédia entre vários pontos. Por um lado, carrego comigo os traços da minha cultura de branca que me diferenciam do modelo de adulto moçambicano e me 
aproximam às crianças: brinco com as crianças, converso com elas, interesso-me pelas suas opiniões... Por outro lado, a quotidianidade da relação com as crianças e o meu estilo de vida me afastam do modelo de "estrangeiro branco" e me assemelham mais à população negra moçambicana: vivo num bairro de periferia, muitas das crianças envolvidas na pesquisa são minhas vizinhas e costumam visitar-me, não tenho carro e ando a pé ou de chapa, vou e volto da escola a pé com as crianças, não tenho água canalizada em casa e vou buscar com os bidões em casa de uma vizinha, faço compras no mercadinho da zona...

Enquanto vou desconstruindo a relação típica adulto/criança, branco/negro, professor/aluno, construo junto com as crianças uma nova relação Elena/crianças. Trata-se de um processo dinâmico, que evolui ao longo de todo o processo de investigação e pode variar na relação com cada criança. Os títulos ou nomes que as crianças me têm atribuído são representativos da fluidez dos processos e das negociações que estão a ser desenvolvidas. É hábito nas escolas moçambicanas que, no momento da entrada do professor na sala, todos os alunos levantem e digam em coro: "Boa tarde, professor/a (nome)”. Nas primeiras entradas nas salas, eu também fui cumprimentada com a frase ritual: "Boa tarde, professora Elena!" Passado algum tempo e depois de ter questionado às crianças sobre o meu papel, criou-se uma certa confusão entre as crianças no momento de me cumprimentar e já não conseguiam acertar o coro habitual: algumas diziam "professora Elena", outras "explicadora Elena", "senhora Elena", ainda outras "pesquisadora Elena” e havia aquelas que diziam simplesmente "Elena". Mesmo fora da sala de aulas, as opiniões eram diferentes e a maneira de chamar-me variava ao longo do tempo e dependendo das crianças: mana, tia, pesquisadora, professora, explicadora, educadora e Elena eram 
as formas mais utilizadas. Em geral, em Moçambique, chamar uma pessoa mais velha diretamente pelo nome é considerado uma falta de respeito, mas muitas crianças sentiram-se à vontade para fazê-lo e eu nunca lhes chamei a atenção. Porém, várias vezes foram outras crianças a não gostar destas atitudes e a corrigir os colegas dizendo: "Estás a chamar de Elena? Será que tem a tua idade ela?"

Concluindo, podemos afirmar que a identidade do investigador e a sua reflexão sobre ela representam um pilar fundamental da investigação. Tal ideia é duplamente válida para esta investigação, uma vez que é enfatizada quer pela Sociologia da Infância, quer pelo Afrocentrismo. A Sociologia da Infância afirma que a reflexividade e as questões éticas desempenham um papel central no processo de investigação com as crianças, não apenas para questionar criticamente o papel da investigadora e as suas convicções, mas também para avaliar a escolha dos métodos de pesquisa e a sua aplicação (Punch, 2002a). O Afrocentrismo considera a retrospeção e a introspeção como elementos fulcrais do método, afirmando que os investigadores devem determinar se e como as suas experiências de vida e as suas convicções influenciam o processo, a partir do desenho da pesquisa até à recolha e à interpretação dos dados (Reviere, 2001).

\section{A metodologia compósita}

De acordo com os princípios da Sociologia da Infância, as crianças não são consideradas como simples objetos de conhecimento, mas como sujeitos de direitos e atores sociais plenos, competentes na formulação de interpretações sobre os seus mundos de vida e reveladores das realidades sociais onde se inserem (Soares; Sar- 
mento; Tomás, 2004). Assim, o uso de uma metodologia compósita, que mobilize uma gama de diferentes métodos e técnicas, quer tradicionais quer inovadores, representa uma forma de investigar a pluralidade de infâncias e ter em consideração as diferentes competências, experiências de vida e identidades sociais das crianças que participam na investigação (idade, género, estrutura do grupo familiar, atividade e nível de formação dos pais, grupo étnico, classe social).

Numa primeira fase, pareceu-me útil desenvolver um período de observação participante das crianças nos momentos de entrada, do intervalo e de saída da escola, caracterizadas por algumas interações e conversas informais, para melhor conhecer os que participam na investigação e conseguir uma maior compreensão dos seus pontos de vista e das suas experiências (Graue; Walsh, 2003). Só depois de construir uma relação com as crianças e ganhar a sua confiança, queria então passar a colocar em prática métodos mais interativos e participativos, que minimizassem o desequilíbrio de poder entre o investigador adulto e as crianças que participam na investigação, existente numa relação face a face. Como já indicado num parágrafo anterior, esta separação temporal dos dois momentos não foi possível e a construção de uma relação com as crianças fora das salas de aula foi acontecendo enquanto já começava a desenvolver algumas atividades participativas com elas nas salas.

\section{Jogo de apresentação}

Como já acenado anteriormente, a primeira atividade proposta às crianças foi um jogo de apresentação muito simples. Uma criança de cada vez parava em frente de todos, dizia o seu nome e 
depois imitava com gestos e sem poder falar a atividade que mais gosta de desenvolver em casa, enquanto o resto da turma tentava adivinhar. Entretanto eu apontava no meu caderno o nome e a atividade preferida de cada criança. Este momento foi importante, por um lado, para mim, para começar a conhecer as crianças, os seus nomes e os seus gostos e, por outro lado, para as crianças iniciarem a familiarizar-se com a minha presença e para ganharem interesse nas atividades que poderiam desenvolver comigo. De facto, alguns dias depois um breve diálogo com uma criança demonstrou-me o seu interesse para que eu voltasse a trabalhar com elas na sala de aula.

\section{Perguntas: 'Queres participar?' e 'Como fazer?'}

Uma vez que a minha ideia era avaliar a escolha dos métodos mais adequados no campo e partilhá-la com as crianças, resolvi propor aos alunos das três turmas de responder por escrito a algumas perguntas que me pudessem fornecer informação relevante sobre às suas intenções em relação à participação na investigação e sobre as maneiras que achavam mais apropriadas para desenvolver o trabalho. Nomeadamente, as perguntas foram as seguintes:

Queres participar no trabalho de pesquisa para conhecer a vida das crianças em Moçambique?

Como fazer para conhecer a vida das crianças?

O que acham mais importante saber para conhecer as crianças e as suas vidas?

As primeiras duas perguntas foram propostas nas três turmas enquanto a terceira apenas numa delas. Todas as crianças, menos uma que por acaso tinha mais proximidade comigo no tempo do 
intervalo, aceitaram formalmente participar do trabalho de investigação. As ideias que sugeriram sobre as formas de conhecer a vida das crianças foram várias e diversificadas mas muitas delas faziam parte dos exemplos de respostas que eu tinha dado na apresentação da atividade. As respostas foram: conversar com as crianças, conversar em grupo, fazer investigações, perguntar o que as crianças fazem em casa e qual é o seu sonho quando forem grandes, fazer um concurso com as criança de todas as províncias de Moçambique nos programas infantis, participar nos teatros, tirar fotografias, fazer vídeos, ir a praia, conhecer as casas das crianças, passear, fazer perguntas e entrevistas, falar com os chefes de quarteirão e com os pais, saber onde moram e se estudam, cumprimentar as crianças, tratá-las com amor e carinho, tratar bem, respeitar, não bater, não berrar, compartilhar no lanche, observar, conviver, fazer amizades, brincar e fazer jogos, conhecer os nomes, fazer teatros e textos, visitar as famílias em outros bairros, ajudar, apoiar os que não têm, oferecer roupas e material escolar, saber o que as crianças gostam, com quem vivem, conhecer várias crianças, seguir os passos delas, aceitar o que as crianças tem a dizer, deixar as crianças contarem histórias, deixarem as crianças dançarem ou qualquer coisa que as crianças querem fazer, fazer cantos e danças, abrir o coração das crianças, arranjar tempo e sentar com a criança para conversar bem com ela, fazer cartazes, relatórios e uma exposição sobre as crianças, como vivem, como são alimentadas e o estado delas, fazer grupos, participar da vida das crianças todos os dias, dar uma palestra sobre a vida das crianças, fazer desenhos em cartolinas e também realizar publicidades para os mais jovens terem noção desta situação, levar alguns objetos como brinquedos para que as crianças possam se divertirem mais, rir com elas, haver uma confiança entre nós e as crianças. 


\section{Questionário coletivo co-construído}

Dado que muitas crianças sugeriram que era importante fazer perguntas às crianças sobre vários assuntos que tinham a ver com as suas vidas, tive a ideia de um "questionário coletivo co-construído", isto é, deixar às crianças a possibilidade de criar as perguntas que elas mesmas em seguida iriam responder. Designadamente, cada criança da turma pensava e enunciava uma pergunta que todos os colegas deviam responder, cada um na sua folha. Às vezes, os colegas criticavam uma pergunta e sugeriam alterações que eram elaboradas também com a ajuda da investigadora. Nos momentos em que nenhuma das crianças tinha uma ideia pronta, eu também aproveitei para propor em forma de perguntas algumas das questões de pesquisa que mais me interessavam. As crianças gostaram desta atividade por um lado, porque lhes deu o papel de protagonistas no momento de formular a pergunta para toda a turma e, por outro lado, porque uma vez que eram as próprias crianças a elaborar as perguntas, estas resultavam para elas "interessantes". Assim, este trabalho produziu uma dupla informação para a pesquisa: as perguntas indicam-nos que aspetos as crianças acham relevantes para conhecer a vida de outras crianças e as respostas fornecem-nos, em pouco tempo, um conjunto notável de informação sobre tais aspetos.

Depois desta atividade senti a necessidade de tomar uma decisão em relação às crianças e às turmas que estariam envolvidas na investigação. Optei por não desistir de nenhuma turma mas continuar a trabalhar com as três nas atividades que não precisavam de 
um envolvimento direto e pessoal da investigadora. Esta decisão foi motivada, por um lado, porque não queria excluir totalmente as crianças realmente interessadas em participar no trabalho que existiam nas três turmas; por outro lado, porque achei interessante recolher uma parte da informação com um universo mais amplo e continuar a manter contactos com as crianças, que podiam eventualmente ser úteis numa outra etapa da investigação.

Em relação aos trabalhos em pequenos grupos que requeriam maiores investimentos em termos de tempo, acompanhamento e envolvimento pessoal, preferi optar por trabalhar com as crianças de uma única turma. A escolha da turma baseou-se na "disciplina” e no interesse das crianças pela pesquisa, elementos que tornavam muito mais fácil o trabalho da investigadora na sala de aula. A partir deste critério, acabei por excluir as duas turmas onde mais crianças me conheciam, uma vez que dentro de poucas semanas o relacionamento era praticamente o mesmo quer com as novas, quer com as antigas "amizades". O que acabou por confirmar a minha escolha foi também o facto de que nas duas turmas que ficaram parcialmente excluídas havia vários alunos mais crescidos, de 14 ou 15 anos, que já poderiam ser considerados adolescente, mais do que crianças. A seguir, apresentamos brevemente cada uma das atividades que foram propostas às crianças das três turmas.

\section{Desenho e/ou texto}

As crianças podiam escolher um título a partir do qual desenvolver um desenho, um pequeno texto ou uma combinação das duas coisas. Os títulos propostos foram: A vida das crianças, Eu e 
a minha família, Eu e os meus irmãos, Eu em casa, Eu a brincar. A ideia seria dar em seguida a possibilidade a cada criança de explicar o que tinha escolhido fazer e o porquê, mas isto não foi possível porque o trabalho foi realizado em turmas numerosas e com pouco tempo a disposição.

\section{Entrevista}

As crianças, em pares, elaboravam um conjunto de perguntas que depois faziam reciprocamente uma a outra e registavam as respostas numa folha. Em alguns casos, as respostas foram também gravadas ou filmadas.

\section{Diário}

Cada criança recebeu um caderno, onde escrever o diário das atividades quotidianas, ao longo de uma semana. Antes de entregar os cadernos, discutiu-se com as crianças o que se considera um diário e depois a investigadora deu algumas indicações relativas à informação que não se poderiam esquecer de escrever cada vez que fossem a preencher o diário: data, hora, onde estava, com quem estava e o que fez. De acordo com Gaitán (2006), através deste instrumento, a criança coloca-se no centro do processo de investigação, expressando-se livremente, oferecendo mais elementos em relação aos previstos pelo investigador e libertando-se do marco preconcebido da investigação. Os diários permitiram recolher uma grande quantidade de dados em um breve intervalo de tempo. 


\section{Filme e questionário}

Apresentou-se às crianças Os caminhos do Ser, um filme que conta o dia a dia de quatro irmãos que vivem sozinhos porque os pais faleceram e veem-se então obrigados a desempenhar todas as tarefas domésticas e a tomar conta uns dos outros. O filme serviu como estímulo no preenchimento do questionário sobre os trabalhos domésticos das crianças e a atividade de tomar conta, que foi proposta em seguida. As perguntas apresentavam, primeiro, um aspeto da situação das crianças do filme e depois pediam para que cada criança fornecesse informação sobre este aspeto na sua vida. O filme revelou-se muito útil para despertar o interesse das crianças em relação à atividade proposta e para oferecer um exemplo visual concreto que pudesse ser utilizado para explorar a vida das crianças e tornar mais claras as próprias perguntas do questionário.

\section{Caixa do 'Correio da pesquisa'}

Na última semana de aulas, foi apresentada a todas as crianças e depois colocada numa das salas, a caixa do "Correio da pesquisa", isso é, uma caixa onde as crianças pudessem deixar qualquer mensagem, assinada ou anónima, relacionada com a vida das crianças, com as atividades de investigação e com a própria investigadora. Designadamente, na caixa estava escrito "A vida das crianças. Ideias, comentários, sugestões, reclamações." Esta ferramenta revelou-se muito importante para ter uma avaliação global do trabalho desenvolvido junto das crianças e para dar espaço a elas de expressar opiniões sem ter de me falar pessoalmente (Punch, 2002b). 
Diversamente, os grupos de trabalho foram constituídos diretamente pelas crianças, uma vez que cada uma delas tinha a possibilidade de escolher em que atividade se colocar, dentro de uma lista que eu elaborei a partir de algumas das respostas que eles tinham dado na pergunta "Como fazer para conhecer a vida das crianças?". As atividades propostas foram cartazes, fotografias, entrevistas, canto e dança, teatro, vídeo, bandas desenhadas e histórias, das quais apenas as últimas três foram excluídas pelas crianças. No princípio e na conclusão do trabalho de cada grupo, realizaram-se pequenos grupos de discussão com os participantes: no primeiro caso, através do uso do diagrama aranha (brainstorming), um material visual para juntar ideias, construir informação e estimular aprofundamentos; no segundo caso, para conhecer o significado que as crianças atribuem ao que foi produzido e recolher as impressões e os comentários sobre as atividades desenvolvidas. Apesar do grupo de discussão ter sido apontado como uma forma de romper as relações de poder desiguais entre crianças e adultos e deixar espaço à expressão espontânea das crianças (Gaitán, 2006), nem sempre isto aconteceu. Às vezes, as crianças ficaram um pouco tímidas e responderam com algumas dificuldades às questões que eu colocava. Elas pediram para que pudessem apresentar o produto dos seus trabalhos aos pais e aos colegas e, de acordo com a direção e os professores, decidiu-se atribuir um espaço a cada grupo no "dia do encerramento do ano" em que participam os alunos, os familiares das crianças, os professores e os funcionários de toda a escola.

\section{Cartazes}

As crianças realizaram cartazes com desenhos e textos, depois de terem discutido por muito tempo sobre os temas a apresentar. 
Mais do que a própria realidade das crianças, este grupo revelou quais são as representações sobre a vida das crianças em geral que as próprias crianças possuem e quais os aspetos que consideram mais relevantes a serem tratados.

\section{Fotografias}

Os métodos autofotográficos consistem na produção e na sucessiva análise de fotografias retiradas pelos próprios sujeitos da investigação. Segundo Santana (2008), o interesse pelas máquinas fotográficas, assim como pelas fotografias produzidas, costuma aumentar o interesse das crianças pelo projeto de investigação. No nosso caso, depois de ter discutido com as crianças quais são as razões que levam as pessoas a tirar fotografias, pediu-se a cada criança que escolhesse e tirasse uma fotografia de uma coisa, um lugar ou uma pessoa que considerasse importante na sua vida na escola. A seguir, pediu-se que as crianças tirassem uma fotografia do que consideravam importante nas suas vidas em geral. Uma vez que várias crianças escolheram os pais, o pretexto da fotografia permitiu que a investigadora conhecesse as casas e as famílias destas crianças. Finalmente, as crianças do grupo reuniram-se para ver e discutir as fotografias tiradas e decidir como organizá-las.

\section{Entrevistas}

As entrevistas foram planificadas e realizadas diretamente pelas próprias crianças. Como no caso do "questionário coletivo co-construído", esta técnica forneceu uma dupla informação, sobre o que as crianças acham relevante perguntar e sobre as respostas que elas dão a tais perguntas. Para além disso, o facto de ser outras 
crianças a conduzir as entrevistas, deixava os entrevistados mais a vontade do que se fosse a investigadora adulta a colocar as perguntas. Por outra, a informação recolhida pelas crianças poderia talvez não resultar tão interessante para a investigadora ao fim de responder às suas questões de partida. No lugar das crianças entrevistadoras, a investigadora adulta teria provavelmente abordado uns temas totalmente diferentes.

\section{Canto}

As crianças deste grupo foram convidadas a criar e apresentar canções que falassem, de alguma maneira, da vida das crianças. Depois de elaborar as letras e as músicas, começaram os ensaios, primeiro na sala ou no pátio e, mais tarde, no palco. Para além da informação fornecida pelos grupos de discussão, pelas letras e pelas músicas criadas pelas crianças, a fase dos ensaios permitiu observar as relações que se instauraram entre as crianças e a negociação entre diferentes ideias sobre a melhor maneira de apresentar-se em público.

\section{Teatro}

O grupo de teatro teve uns primeiros encontros em que a investigadora propunha às crianças alguns exercícios para as capacitar a representar diferentes personagens e situações. Em seguida, pediu-se às crianças para pensar e apresentar uma pequena peça que tratasse algum aspeto da vida das crianças. $O$ trabalho foi bastante difícil e não se chegou a produzir nenhuma peça para ser 
apresentada por causa da escassa familiaridade das crianças com a linguagem teatral e das dificuldades em organizar-se e trabalhar em grupo.

\section{Observação}

Finalmente, a observação constitui-se como o primeiro método utilizado no trabalho de campo e que continua a ser utilizado ao longo de todo o processo. Trata-se de uma observação seletiva com registo sistemático de todo o observado. Esta atividade é necessária para especificar as perguntas iniciais da investigação, recolher informação sobre o contexto da pesquisa, acompanhar e registar a recolha de dados através de outros métodos e técnicas, verificar e complementar a informação obtida através de outros métodos e fontes. Designadamente, alternam-se momentos de observação não interativa e participante: nos primeiros, a investigadora não procura relacionar-se com as crianças e, pelo contrário, faz de conta que não está a acompanhar ou não está interessada no que acontece ao seu redor, para que as crianças não mudem o seu comportamento e as suas conversas pelo facto de estarem a ser observadas por um adulto; nos segundos, a investigadora está disponível ou mesmo procura interagir com as crianças integrando-se na situação em que elas se encontram e, se possível, desempenhando a mesma atividade.

Diversamente da O'Kane (2005), que afirma ter selecionado as técnicas participativas como uma alternativa aos métodos etnográficos, consideramos que não existe incompatibilidade entre os dois métodos; pelo contrário, a observação etnográfica pode representar um elemento complementar de grande importância nas metodologias participativas. De facto, de acordo com Soares, Sar- 
mento e Tomás (2004), as possibilidades de escolha dos dispositivos metodológicos mais apropriados para a pesquisa são imensas e decorrem essencialmente da criatividade dos implicados no design da investigação, sejam eles adultos ou crianças.

\section{Em jeito de conclusão: qual participação das crianças?}

A participação ativa das crianças na pesquisa e a liberdade a elas garantida de expressarem as suas opiniões livremente sobre todos os assuntos relacionados com elas não constitui apenas uma opção metodológica no âmbito da investigação, mas um direito estabelecido no artigo 12 da Convenção sobre os Direitos da Criança. Mesmo assim, trabalhar num determinado contexto histórico e cultural, no qual o respeito pela autoridade e pela sabedoria dos mais velhos acaba por marginalizar as vozes e os saberes das crianças, coloca aos investigadores grandes desafios para encontrar formas de quebrar o poder desigual entre adultos e crianças e criar espaços que permitam às crianças terem voz e sobretudo se sentirem livres de expressar as suas ideias.

De acordo com Soares, Sarmento e Tomás (2004), é possível identificar diferentes patamares de participação das crianças na investigação, dependendo das etapas e das atividades em que estas são envolvidas. No caso da pesquisa aqui apresentada, foi pedido o consentimento das crianças em participar numa investigação que tinha o objetivo de conhecer "a vida das crianças em Moçambique", tratou-se intencionalmente de um objetivo muito amplo que deixava muito espaço para negociar com as crianças os conteúdos a serem aprofundados e as formas como trabalhar.

O principal choque foi representado pela intenção da investiga- 
dora de desenvolver uma investigação participativa num contexto em que não é habitual que os adultos peçam às crianças a sua participação e contribuição em termos de ideias e opiniões. O que geralmente é exigido às crianças, quer em casa como na escola, é obedecer, armazenar conhecimentos sem questioná-los, conformar-se às normas. O que aconteceu então foi que nos momentos "institucionalizados" da pesquisa, as crianças se conformavam à norma, aos discursos e aos estereótipos vigentes na sociedade, enquanto apenas nos momentos "livres", que consideravam estar fora dos contornos do trabalho de investigação, chegavam a falar da sua realidade pessoal. Para esclarecer esta ideia, apresentamos aqui o exemplo de uma menina de dez anos.

Dinha, ao responder à pergunta "Com quem vives?" no "questionário coletivo co-construído", escreve que vive com o pai, a mãe e as irmãs. Dias depois, num sábado, saindo juntas da escola onde estávamos para um ensaio, ela explica-me onde mora e, em seguida, convida-me a conhecer a sua casa. Eu aceito e, pelo caminho, pergunto com quem vive, sem conhecer a resposta que tinha dado no questionário. Ela responde que vive com a mãe, a avó e as irmãs, enquanto o pai vive numa outra zona com a mulher dele. Uma vez em casa, a mãe explica-me a mesma situação. Na semana seguinte, Dinha é entrevistada por uma colega com o gravador na mão, durante um encontro do grupo das entrevistas do qual faz parte.

Entrevistadora: "Com quem vives?"

Dinha: "Com a minha mãe e o meu pai."

Entrevistadora: "Só?"

Dinha: "Com a minha mãe, o meu pai e as minhas irmãs!" A entrevistadora passa à pergunta seguinte, enquanto eu assisto à cena de longe sem falar nada.

Nos momentos considerados "oficiais" da pesquisa, é visível a falta de hábito de participar dentro das formas propostas. Duas 
consequências disso tornam-se evidentes sobretudo nos trabalhos em grupo: por um lado as crianças, interrogadas sobre "a vida das crianças em Moçambique", nunca falam das suas experiências pessoais e concretas, mas referem-se sempre ou a conceitos abstratos, como os direitos das crianças, ou a outras crianças de quem ouviram falar ou que viram na rua ou na televisão; por outro lado, falando destas outras crianças, dificilmente utilizam um conhecimento direto mas quase sempre baseiam-se em imagens de crianças fortemente estereotipadas (as crianças de rua, as crianças órfãs, as crianças pobres...) e manifestam uma abordagem assistencialista, de querer ajudar.

Uma possível explicação do facto que as crianças não falem de si mesmas pode ser uma baixa autoestima. As crianças podem talvez não considerar relevante e interessante falar de si mesmas e das próprias experiências e procuram contar histórias de outras crianças que nem conhecem. É também possível que não se trate de um baixo nível de autoestima das crianças, mas sim de uma questão cultural ligada a um processo de socialização que induz silêncio sobre a identidade pessoal, enfatizando a expressão de uma consciência discursiva sobre o grupo.

Em relação ao facto de as crianças insistirem no discurso dos Direitos da Criança e falarem das outras crianças através de estereótipos, reproduzindo os discursos governativos que são divulgados através dos mass media e dos próprios programas escolares, podemos referir-nos ao sociólogo Elísio $\mathrm{Macamo}^{3}$, que aponta para as dificuldades dos estudantes moçambicanos em desenvolver um pensamento crítico e criativo. Segundo a sua análise, tais dificuldades dependem do próprio processo de socialização, durante o qual as crianças em casa aprendem que não se pode questionar a autoridade e a sabedoria dos "mais velhos"; daí decorrem 
os constrangimentos em questionar e pôr em discussão o que se aprende na escola, o que se assiste na rádio ou na televisão, o que diz a tradição e, a um nível mais amplo, o sistema em si, a política e as autoridades.

Estas conclusões permitem-nos confirmar como o estudo do grupo social da infância representa uma forma de entender a sociedade no seu complexo. De acordo com Sarmento (2000), “[...] ao estudar a infância, não é apenas com as crianças que a disciplina se ocupa: é, com efeito, a totalidade da realidade social o que ocupa a Sociologia da Infância. Que as crianças constituem uma porta de entrada fundamental para a compreensão dessa realidade é o que é, porventura, novo e inesperado no desenvolvimento recente da disciplina. [...] A condição social da infância é, em qualquer sociedade, bem expressiva da realidade social no seu conjunto."

Em relação à escolha dos métodos de pesquisa, atestamos que nenhuma técnica de investigação é naturalmente participativa, sendo que a forma como esta é aplicada, o contexto da investigação e as características dos sujeitos envolvidos determinam o seu caráter mais ou menos participativo (Boyden; Ennew, 1997; Santana, 2008). Para que as técnicas participativas se tornem num método de investigação viável tem sido sugerido que sejam utilizadas num contexto de diálogo contínuo com as respetivas crianças (O’Kane, 2005).

Uma investigação levada a cabo em tempos, espaços e situações diferentes, através do uso de uma vasta gama de ferramentas sempre acompanhadas por uma observação mais ou menos participante, oferece-nos uma descrição e uma compreensão ricas da realidade observada, porque consideram perspetivas diversificadas. No caso aqui descrito, enquanto os trabalhos em grupo apresentaram as representações das crianças sobre o que "a vida das 
crianças em Moçambique" deveria ser (discurso dos direitos) ou é considerada ser (estereótipos das crianças órfãs e vulneráveis), as técnicas escritas e a observação participante permitiram conhecer a realidade do dia a dia das crianças envolvidas na pesquisa. É exatamente esta a força da metodologia compósita: uma combinação de métodos e técnicas que torna visíveis diferentes faces de uma mesma realidade, oferecendo às crianças a oportunidade de se expressar através das suas múltiplas linguagens (escrita, oral, visual, corporal, artística...).

É também nesta direção que apontam as palavras de Bento, um menino de 12 anos que participou da pesquisa, enfatizando a necessidade de deixar abertos todos os caminhos que as crianças queiram percorrer, no âmbito da investigação:

Para conhecer a vida das crianças deve-se aceitar o que as crianças têm a dizer, deixar as crianças contarem histórias, deixarem as crianças dançarem ou qualquer coisa que as crianças querem fazer e também nós crianças devemos respeitar as pessoas que querem nos conhecer e facilitar, não fazer barulho. (Bento, trabalho realizado na sala, 22/08/2008).

Uma pergunta permanece então aberta para todos os investigadores da infância: como será possível levar em consideração todas as ideias e as sugestões das crianças e, ao mesmo tempo, fazer com que a investigação seja viável?

\section{Referências}

ALDERSON, P. Listening to children. Children, ethics and social research. London: Barnardo's, 1995. 
O USO DE METODOLOGIAS PARTICIPATIVAS NA INVESTIGAÇÃO COM CRIANÇAS: ALGUMAS CONSIDERAÇÕES A PARTIR DE UMA PESQUISA NA PERIFERIA DE MAPUTO

; MORROW, V. Ethics, social research and consulting with children and young people. Barkingside: Barnardo's, 2004.

BOYDEN, J.; ENNEW, J. Children in focus: a manual for participatory research with children. Stockholm: Radda Barnen, 1997.

CORSARO, W. The Sociology of childhood. California: Pine Forge Press, 1997.

; MOLINARI, L. Entrando e Observando nos Mundos da Criança. In: CHRISTENSEN, P.; JAMES, A. (Orgs.). Investigação com Crianças: perspectivas e práticas. Porto: Escola Superior de Educação de Paula Frassineti, 2005.

GAITÁN, L. Sociología de la Infancia. Madrid: Editorial Síntesis, 2006.

GRAUE, E.; WALSH, D. Investigação etnográfica com crianças: teorias, métodos e ética. Lisboa: Fundação Calouste Gulbenkian, 2003.

O'KANE, C. O desenvolvimento de técnicas participativas. In: CHRISTENSEN, P.; JAMES, A. (Orgs.). Investigação com Crianças: perspectivas e práticas. Porto: Escola Superior de Educação de Paula Frassineti, 2005.

PUNCH, S. Childhoods in the majority world: miniature adults or tribal children? Sociology, n. 37, p. 277-295, 2003.

Interviwing Strategies with Young People: the 'Secret Box', Stimulus Material and Task-based Activities. Children \& Society, n. 16, p. $45-56,2002 b$.

. Research with children: the same or different from research with adults? Childhood, n. 9, p. 321-341, 2002a.

REVIERE, R. Toward an Afrocentric Methodology. Journal of Black Studies, n. 31, p. 709-728, 2001.

SANTANA, J. Cotidiano, expressões culturais e trajetórias de vida: uma investigação participativa com crianças em situação de rua. 2008. Tese (Doutoramento) - Instituto de Estudos da Criança, Universidade do Minho, Braga, 2008. 
SARMENTO, M. J. Sociologia da Infância: Correntes e Confluências. Cadernos do Noroeste: Série Sociológica, v. 13, n. 2, 2000.

SOARES, N.; SARMENTO, M. J.; TOMÁS, C. Investigação da infância e crianças como investigadoras: metodologias participativas dos mundos sociais das crianças. 2004. Disponível em: <http://cedic.iec.uminho.pt/ Textos_de_Trabalho/menu_base_text_trab.htm $>$. Acesso em: 20 jun. 2007.

THOMAS, N.; O'KANE, C. The Ethics of Participatory Research with Children. Children \& Society, n. 12, p. 336-348, 1998.

\section{NOTAS}

${ }^{1} \mathrm{O}$ presente artigo representa uma versão parcial do capítulo metodológico da tese de doutoramento da autora "Eu é que fico com a minha irmã. Vida quotidiana das crianças na periferia de Maputo." Uma versão preliminar deste texto foi publicada em 2011 no livro Mosaico Sociológico, organizado por Nair Teles, Baltazar Muianga e Eugénio Brás.

${ }^{2}$ Doutorada em Sociologia da Infância, Investigadora do CIEC da Universidade do Minho e professora da Universidade São Tomás de Moçambique. E-mail: <elenamaputo@yahoo.it>.

${ }^{3}$ Palestra Que Moçambique? Que Sociologia? Que Currículo?, apresentada pelo professor doutor Elísio Macamo em Maputo, Faculdade de Letras e Ciências Sociais da UEM, no dia 18 de setembro de 2008. 